\title{
Composição química, atividade bactericida e antioxidante dos óleos essenciais das folhas de Ocimum basilicum e Ocimum gratissimum (Lamiaceae)
}

\author{
Chemical composition, bactericidal, and antioxidant activity of the essential oils in the leaves of \\ Ocimum basilicum and Ocimum gratissimum (Lamiaceae)
}

Composición química, bactericida y actividad antioxidante de los aceites esenciales en las hojas de Ocimum basilicum y Ocimum gratissimum (Lamiaceae)

Recebido: 12/06/2021 | Revisado: 19/06/2021 | Aceito: 07/07/2021 | Publicado: 17/07/2021

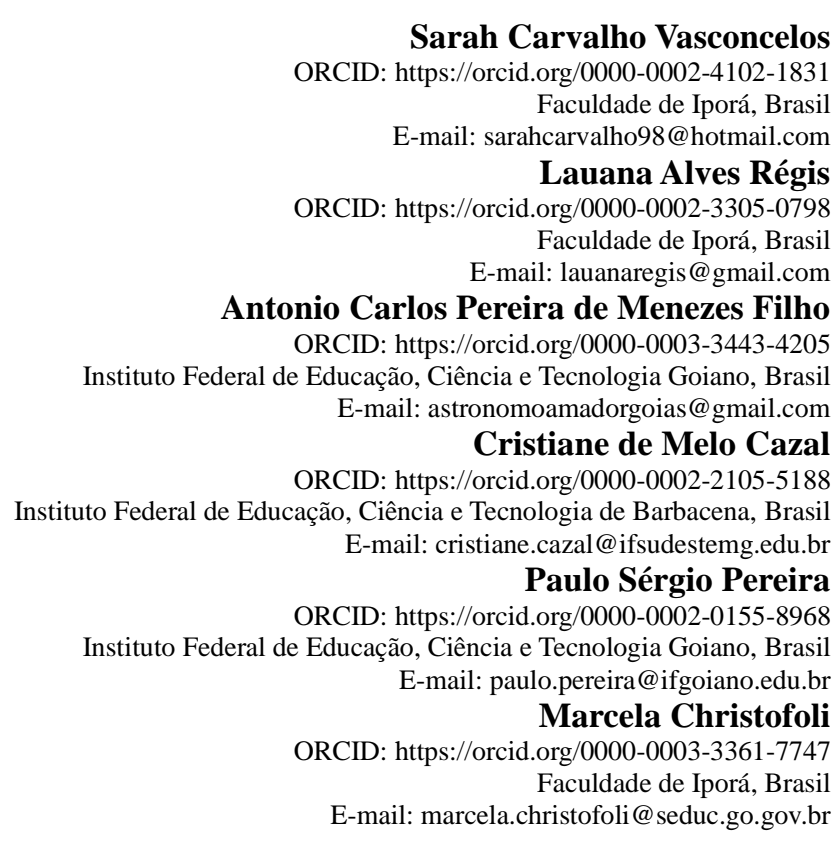

\begin{abstract}
Resumo
O gênero Ocimum da família Lamiaceae compreende um grupo de plantas bem conhecidas como Ocimum gratissimum L. (alfavaca) e Ocimum basilicum (manjericão). Estudos revelam que essas plantas apresentam atividade antimicrobiana, inseticida, antioxidante, antifúngica, analgésica e imunoestimulante. Neste contexto, o objetivo deste estudo foi analisar a composição química dos óleos essenciais de $O$. gratissimum e $O$. basilicum coletadas em diferentes horários e com diferentes tempos de extração, bem como, avaliar sua atividade antioxidante, o teor de fenólicos totais e atividade bactericida sobre Staphylococcus aureus e Escherichia coli. O óleo essencial foi obtido por hidrodestilação em aparelho tipo Clevenger, e a composição química realizada por cromatógrafo gasoso acoplado ao espectrômetro de massas (CG-EM); a análise da atividade antioxidante foi realizada em microplacas de 96 poços com adição de 2,2-difenil-1-picrilhidrazil (DDPH) em metanol; o teor de fenólicos totais foi realizado em microplacas de 96 poços utilizando Folin-Ciocalteu para determinação do teor de ácido gálico; e a atividade bactericida realizada por método de difusão de discos na placa de Petri e método de difusão em meio Muller-Hinton em placas de 96 poços. O maior rendimento do óleo essencial de $O$. gratissimum foi de $0,44 \%$, quando coletado no período da manhã, enquanto o óleo essencial de $O$. basilicum teve rendimento de $0,38 \%$ quando coletado no período da tarde, ambos, com quatro horas de extração. Os compostos majoritários de $O$. gratissimum foram eugenol e eucaliptol, enquanto os compostos majoritários do óleo essencial de $O$. basilicum foram eugenol, $\beta$-linalool e muurolol. A atividade antioxidante foi de $100 \%$ de sequestro do radical livre DPPH nas maiores concentrações de óleo essencial 15,6 $\mu \mathrm{g} \mathrm{mL}^{-1}$, tanto para $O$. gratissimum quanto $O$. basilicum. $\mathrm{O}$ teor de compostos fenólicos totais dos óleos essenciais de $O$. gratissimum e $O$. basilicum foi $=17,90$ e $16,44 \mathrm{mg}$ EAG $100 \mathrm{~g}^{-1}$, respectivamente. Os óleos essenciais de $O$. gratissimum e $O$. basilicum apresentaram $100 \%$ e $83 \%$ de atividade bactericida sobre Staphylococcus aureus e de $100 \%$ a $66 \%$ sobre Escherichia coli, respectivamente, destacando assim o potencial biotecnológico desses óleos essenciais.
\end{abstract}

Palavras-chave: Compostos fenólicos; Staphylococcus aureus; Escherichia coli; Atividade antioxidante. 


\begin{abstract}
The Ocimum genus of the Lamiaceae family comprises a group of well-known plants such as Ocimum gratissimum L. (lavender) and Ocimum basilicum (basil). Studies reveal that plants have antimicrobial, insecticidal, antioxidant, antifungal, analgesic and immunostimulant activity. Thus, the objective of this study was to analyze the chemical composition of the essential oils of $O$. gratissimum and $O$. basilicum collected at different times and with different extraction times, as well as to evaluate their antioxidant activity, total phenolic content and activity bactericide on Staphylococcus aureus and Escherichia coli. The essential oil was obtained by hydrodistillation in a Clevenger type apparatus, and the chemical composition was carried out in a gas chromatograph coupled to the mass spectrometer (GC-MS); the analysis of antioxidant activity was performed in 96-well microplates with the addition of 2,2-diphenyl1-picrylhydrazyl (DDPH) in methanol; the total phenolic content was carried out in 96-well microplates using FolinCiocalteu to determine the gallic acid content; and the bactericidal activity performed by the method of diffusion of discs in the Petri dish and method of diffusion in Muller-Hinton broth in 96-well plates. The highest yield of the essential oil of $O$. gratissimum was $0.44 \%$ when collected in the morning, while the essential oil of $O$. basilicum had a yield of $0.38 \%$ when collected in the afternoon, both with four hours of extraction. The major compounds of $O$. gratissimum were eugenol and eucalyptol, while the major compounds of the essential oil of $O$. basilicum were eugenol, $\beta$-linalool and muurolol. The antioxidant activity was $100 \%$ free radical scavenging DPPH in the highest concentrations of essential oil $15.6 \mu \mathrm{g} \mathrm{mL}^{-1}$ for both, $O$. gratissimum and $O$. basilicum. The total phenolic compounds content of the essential oils of $O$. gratissimum and $O$. basilicum was 17.90 and $16.44 \mathrm{mg}$ AGE $100 \mathrm{~g}^{-1}$ respectively. The essential oils of $O$. gratissimum and $O$. basilicum presented $100 \%$ and $83 \%$ of bactericidal activity against Staphylococcus aureus, and the $100 \%$ to $66 \%$ on Escherichia coli, respectively, thus highlighting the biotechnological potential of these essential oils.
\end{abstract}

Keywords: Phenolic compounds; Staphylococcus aureus; Escherichia coli; Antioxidant activity.

\title{
Resumen
}

El género Ocimum de la familia Lamiaceae comprende un grupo de plantas conocidas como Ocimum gratissimum L. (lavanda) y Ocimum basilicum (albahaca). Los estudios revelan que las plantas tienen actividad antimicrobiana, insecticida, antioxidante, antifúngica, analgésica e inmunoestimulante. Así el objetivo de este estudio fue analizar la composición química de los aceites esenciales de $O$. gratissimum y $O$. basilicum recolectados en diferentes momentos y con diferentes tiempos de extracción, así como evaluar su actividad antioxidante, contenido de fenólicos totales y actividad antioxidante y bactericida sobre Staphylococcus aureus y Escherichia coli. El aceite esencial se obtuvo por hidrodestilación en un aparato tipo Clevenger, y la composición química se realizó en cromatógrafo de gases acoplado al espectrómetro de masas (CG-EM); el análisis de la actividad antioxidante se realizó en microplacas de 96 pocillos con la adición de 2,2-difenil-1-picrilhidrazilo (DDPH) en metanol; el contenido de fenólicos totales se realizó en microplacas de 96 pocillos utilizando Folin-Ciocalteu para determinar el contenido de ácido gálico; y la actividad bactericida fue realizada por método de difusión en discos en la placa de Petri, y el método de difusión en caldo Muller-Hinton en placas de 96 pocillos. El mayor rendimiento del aceite esencial de $O$. gratissimum fue $0,44 \%$ cuando se recogió por la mañana, mientras, que el aceite esencial de $O$. basilicum tuvo rendimiento 0,38\% cuando se recogió por la tarde, ambos con cuatro horas de extracción. Los compuestos principales de O. gratissimum fue eugenol y eucaliptol, mientras que los compuestos principales del aceite esencial de $O$. basilicum fue eugenol, $\beta$-linalol y muurolol. La actividad antioxidante fue $100 \%$ de eliminación de radicales libres DPPH en las concentraciones más altas del aceite esencial $15,6 \mu \mathrm{g} \mathrm{mL} \mathrm{mL}^{-1}$, tanto para $O$. gratissimum y $O$. basilicum. El contenido total de compuestos fenólicos de los aceites esenciales de O. gratissimum y O. basilicum fue 17,90 y 16,44 mg EAG $100 \mathrm{~g}^{-1}$, respectivamente. Los aceites esenciales de O. gratissimum y O. basilicum mostraron $100 \%$ y $83 \%$ de actividad bactericida sobre Staphylococcus aureus, y 100\% al 66\% sobre Escherichia coli respectivamente, destacando el potencial biotecnológico de los aceites esenciales.

Palabras clave: Compuestos fenólicos; Staphylococcus aureus; Escherichia coli; Actividad antioxidante.

\section{Introdução}

Óleos essenciais (OE) são misturas de substâncias complexas e voláteis, lipofílicas, líquidas (oleosa) que contêm peso molecular baixo, e a maioria das vezes é constituída por moléculas de natureza terpênica, geralmente extraídos dos órgãos vegetais como flores, folhas, cascas, rizomas e frutos por arraste a vapor d'água, hidrodestilação ou expressão de pericarpo de frutos cítricos, porém, existem métodos que também são utilizados em indústrias como a enfleurage ou enfloração, extração por $\mathrm{CO}_{2}$ supercrítico e por solventes orgânicos apolares (Morais, 2009).

Esses compostos naturais do metabolismo especial possuem grande aplicação na perfumaria, cosmética, alimentos e como coadjuvantes em medicamentos. São empregados principalmente como aromas, fragrâncias, fixadores de fragrâncias, em composições farmacêuticas e comercializadas na forma in natura ou beneficiados, fornecendo substâncias purificadas como o 
limoneno, citral, citronelal, eugenol, mentol e safrol (Bizzo; Rovell; Rezende, 2009). Os OEs são geralmente conhecidos pela fragrância, além de suas propriedades fungicidas, antivirais, bactericidas e medicinais, sendo usados como antimicrobianos, analgésicos, sedativos e anti-inflamatórios (Araujo et al., 2018).

$\mathrm{O} \mathrm{OE}$ de Ocimum basilicum, por exemplo, apresenta como principal atividade ação antimicrobiana para bactérias Gram-positivas e Gram-negativas como Bacillus cereus, Bacillus subtilis, Pseudomonas aeruginosa, Listeria monocytogenes, Escherichia coli, Staphylococcus aureus, dentre outras (Alves et al., 2010). Na medicina alternativa se utiliza as folhas e flores de $O$. basilicum para preparo de chás, onde possuem propriedades tônicas e digestivas, além de ajudar no tratamento de problemas respiratórios, dores reumáticas e em períodos de crises epilépticas (Colombare et al., 2011; Blank et al., 2009). O $O$. basilicum é uma espécie vegetal da família Lamiaceae, popularmente conhecida como manjericão, apresentando grande interesse na área ornamental, como condimento, na aromaterapia, na medicina, bem como, nas indústrias farmacêutica e cosméticos, principalmente ao fato de apresentar não apenas características medicinais, mas também baixo custo de produção (Ferreira; Henrique; Nunes, 2017). Dentre suas características $O$. basilicum apresenta atividade antioxidante, antimicrobiana e antifúngica (Affini et al., 2017), além disso, pode ser utilizado como antisséptico, antiespasmódico, vermífugo, carminativo, diurético, expectorante e estimulante do córtex adrenal (Amaral, 2015).

Outra espécie pertencente à família Lamiaceae é o Ocimum gratissimum, conhecido popularmente como "alfavaca", podendo ser cultivado em quase todos os tipos de solos no mundo, por apresentar diversos compostos especiais em inúmeras classes como (alcalóides, taninos, flavonoides, compostos fenólicos, óleo essencial (timol, cimen-8-ol, eugenol e Transcariofileno)), pode-se perceber sua grande importância nas indústrias para produção de fármacos, cosméticos e perfumes (Bezerra; Cruz, 2017; Chópite et al., 2012). Estudos retratam que extratos e/ou OE das folhas de O. gratissimum apresentam eficácia no controle de Haemonchus contortus, parasita helmíntico encontrado em pequenos ruminantes; além disso, outros compostos presentes possuem atividade inseticida, nematicida, fungistática e antimicrobiana. Já o eugenol presente com maior quantitativo na planta contém atividades analgésica, antimicrobiana, antifúngica e imunoestimulante (Chópite et al., 2012; Abe et al., 2018).

As bactérias são organismos unicelulares de extrema importância nos processos evolutivos da vida no planeta. No entanto, existem espécies de bactérias que podem trazer danos à saúde (humana e animal), além daquelas envolvidas na deterioração de produtos alimentícios, deixando-os impróprios para o consumo (Abdou et al., 2007; Negi, 2012). Inúmeras vezes, o controle do crescimento bacteriano torna-se inviável ou até mesmo impossível, fato este, relacionado à capacidade que os microrganismos possuem em adquirir resistência as mais variadas formas de tratamento, tanto físico quanto químico, como antibióticos e antifúngicos (Silva et al., 2018).

Staphylococcus aureus possui ampla distribuição, devido ao fato de serem resistentes á dessecação e ao frio, podendo permanecer viável por longos períodos em partículas de poeira (Junior et al., 2018). Segundo os autores, trata-se de uma bactéria encontrada com relativa frequência no ambiente de circulação do ser humano, sendo o próprio homem seu principal reservatório, apresentando-se ainda em diversas partes do corpo, como fossas nasais, pele, garganta e intestino.

Escherichia coli é classificada como variantes de acordo com a caracterização dos antígenos somáticos e denominadas de acordo com as infecções intestinais (Junior et al., 2018). De acordo com os autores, alguns sorovares de E. coli não estão relacionados a certas patologias, pois as mesmas também estão presentes na flora natural do trato intestinal do homem, porem, devido aos seus fatores de virulência podem adaptar-se a novos ambientes e em alguns casos causarem doenças graves, como infecção urinaria, doenças respiratórias e pneumonia.

Esses dentre outros patógenos são os responsáveis por inúmeros casos de intoxicação e/ou infecções alimentares, uma vez que são veiculadas pela água ou alimentos contaminados (Thanissery et al., 2014; Alali et al., 2013; Fda, 2010). Essas bactérias são amplamente distribuídas no meio ambiente, o que contribui para seu elevado impacto na saúde pública (Back, 
2011). Por esse motivo, alguns estudos têm sido realizados no controle desses microorganismos. Os OEs de Ferula assafoetida foram avaliados quanto a sua atividade sobre inúmeros microorganismos, entre eles E. coli e S. aureus (Zomorodian et al., 2018). Benjemaa et al. (2018) também avaliaram a atividade bactericida promovida por Thymus capitatus sobre cepas de $E$. coli.

Associada ao controle microbiológico em alimentos, outra aplicação de destaque dos OEs é a sua adição aos óleos comestíveis e outros alimentos com potencial agente antioxidante natural para inibir a deterioração oxidativa, mantendo assim a qualidade e prolongando o prazo de validade do produto alimentar (Siddique et al., 2017). Os antioxidantes vegetais também são conhecidos como sinônimos de nutracêuticos, que são compostos químicos com propriedades redutoras, e tem sido muito utilizados na indústria de alimentos para proteção de um produto orgânico contra a oxidação, além do interesse devido sua capacidade de combater o estresse oxidativo em biomoléculas (Oh; Shahidi, 2018).

Os compostos fenólicos são produtos especiais do metabolismo vegetal fazendo parte de um amplo e complexo grupo de fitomoléculas que possuem em sua estrutura ao menos um anel aromático com uma ou mais hidroxilas (Araujo et al., 2018). Devido sua natureza fitoquímica, atuam como agentes redutores interrompendo a cadeia de reação da oxidação através da doação de elétrons ou de hidrogênio aos radicais livres, convertendo-os em produtos termodinamicamente estáveis, e/ou complexando com metais e componentes iniciadores da oxidação lipídica. Ao retardar a oxidação, eles também podem impedir certas doenças relacionadas ao estresse oxidativo, como lesões de pele, aterosclerose, disfunção, cânceres e distúrbios inflamatórios dentre outros (Oh; Shahidi, 2018).

Por esses motivos, o uso de compostos naturais como aditivos possuem potencial demanda em crescimento. As propriedades antioxidantes de diversas espécies de vegetais têm sido avaliadas buscando aplicação na indústria alimentícia e farmacêutica, com destaque para o tomilho (Thymus vulgaris), o cravo-da-índia (Eugenia caryophyllata), a canela (Cinnamomum parthenoxylon), erva-cidreira (Melissa officinalis L.), cedro (Cedrus libani), limão (Citrus limon (L.) Burm), tangerina (Citrus reticulata Blanco), alecrim (Rosmarinus officinalis L.), orégano (Origanum vulgare L.), salvia (Salvia officinalis L.), manjericão (Ocimum basilicum L.), espinheira santa (Maytenus ilicifolia Mart.) dentre outros (Mezza et al., 2018; Olszowy \& Dawidowicz, 2016; Amorati et al., 2013; Amiri, 2012; Negri et al., 2009).

Nesse sentido, o presente estudo teve por objetivo avaliar os fatores como horário de coleta e tempo de extração na composição química dos óleos essenciais das folhas de $O$. basilicum e $O$. gratissimum além de avaliar a atividade antioxidante, o teor de compostos fenólicos totais, e a atividade bactericida sobre cepas de S. aureus e E. coli.

\section{Metodologia}

\subsection{Coleta do material vegetal}

As folhas de $O$. basilicum e $O$. gratissimum foram coletadas na cidade de Iporá, Goiás, Brasil, com as seguintes coordenadas geográficas $\left(16^{\circ} 26^{\prime} 15^{\prime \prime} \mathrm{S}\right.$; 51 $1^{\circ} 07^{\prime} 21^{\prime}$ 'W), em diferentes horários do dia (manhã: 07:00 e tarde: 14:00 horas) para avaliar a influência do horário de coleta no rendimento dos OEs. Após a coleta, acondicionou-se o material em sacos plásticos umedecidos com água, para manter a hidratação das folhas durante o transporte até o local de extração.

\subsection{Obtenção do óleo essencial}

Os OEs das folhas de $O$. basilicum e $O$. gratissimum, foram extraídos por hidrodestilação. O material vegetal fresco constituído de $100 \mathrm{~g}$ de folhas de $O$. basilicum e $O$. gratissimum foram trituradas utilizando $500 \mathrm{~mL}$ de água destilada, e submetidas ao processo de hidrodestilação em diferentes intervalos de tempo com o auxílio de um aparelho Clevenger. O hidrolato foi extraído com $30 \mathrm{~mL}$ de diclorometano, e em seguida, seco com sulfato de sódio anidro. O solvente foi removido 
em temperatura ambiente, e o $\mathrm{OE}$ foi armazenado em refrigerador a $-12{ }^{\circ} \mathrm{C}$ até as análises. Calculou-se o rendimento percentual de OE conforme equação:

$$
\text { Rendimento } \%=\frac{\text { massa de óleo essencial }}{\text { massa de material vegetal }}: 100
$$

\subsection{Análise química do óleo essencial}

Os constituintes químicos dos OEs foram analisados no laboratório de Química de Produtos Naturais da Universidade Federal de São Carlos (UFSCar) por cromatografia a gás acoplado ao espectrômetro de massas sequencial (CG-EM/EM). O cromatógrafo é equipado com coluna Restek Rtx-5ms (30m x 0,25 mm x 0,25 $\mu \mathrm{m}$ ) fundida com sílica, auto-injetor (Combi PAL AOC-5000 Shimadzu), espectrômetro de massas sequencial (MS TQ8030; Shimadzu) e detector por ionização por impacto eletrônico (IE) $(70 \mathrm{eV})$.

O Software utilizado foi GC-EM Real Time Analysis ${ }^{\circledR}$. As condições de análise foram: temperatura do injetor: 230 ${ }^{\circ} \mathrm{C}$, temperatura do detector: $300{ }^{\circ} \mathrm{C}$, pressão de injeção: $57,4 \mathrm{KPa}$, razão de Splitless: 150 , faixa de detecção do espectrômetro de massas: $43-550 \mathrm{~m} / \mathrm{z}$, start time (cut time do solvente): 3,0 min e fluxo de $3 \mathrm{~mL} \mathrm{~min}^{-1}$. Condições da rampa foram: temperatura inicial de $60{ }^{\circ} \mathrm{C}$ mantida por $3,0 \mathrm{~min}$, acrescida de $3{ }^{\circ} \mathrm{C} \mathrm{min}^{-1}$ até atingir $200{ }^{\circ} \mathrm{C}$ e posteriormente programada para um aumento de temperatura de $15^{\circ} \mathrm{C} \mathrm{min}^{-1}$ até $280^{\circ} \mathrm{C}$, permanecendo nessa temperatura por mais $1,0 \mathrm{~min}$.

A identificação dos componentes do OE baseou-se no índice de retenção linear - índice de Kovats (IK), calculado em relação aos tempos de retenção da série homóloga de $n$-alcanos (C-7 a C-40) e no padrão de fragmentação observando nos espectros de massas, por comparação destes com dados da literatura (ADAMS, 2007) e da espectroteca Nist 11.

Após a análise da composição química os OEs obtidos de matéria vegetal coletados em diferentes períodos do dia e em diferentes tempos de extração, foram reunidos e homogeneizados para realização dos ensaios subsequentes (teor de fenólicos totais, atividade antioxidante e bactericida).

\subsection{Teor de compostos fenólicos totais}

O ensaio do teor de fenólicos totais foi realizado de acordo com Tohidi et al. (2017), com adaptações para microplacas de 96 poços para que pudesse obter uma economia dos reagentes. Em cada poço da microplaca, foi adicionado $25 \mu \mathrm{L}$ de solução metanólica do OE $\left(25 \mathrm{mg} \mathrm{mL}^{-1}\right)$ e $175 \mu \mathrm{L}$ de Folin-Ciocalteu, diluído em metanol na proporção 1:10 ( $\left.v / v\right)$. O sistema foi mantido em repouso no escuro por 2 horas em BOD a $25^{\circ} \mathrm{C}$ e em seguida, foi submetido à leitura em espectrofotômetro (VersaMax Tunable ${ }^{\mathrm{TM}}$ - Molecular Devices - Sunnyvale, CA, EUA) a $765 \mathrm{~nm}$, tendo todo experimento realizado em triplicata.

Para que pudesse quantificar o teor de fenólicos totais, preparou-se seis diluições de ácido gálico $(1 ; 2 ; 4 ; 6 ; 8$ e $10 \mathrm{mg}$ $\mathrm{mL}^{-1}$ ), que foram submetidas a leituras em espectrofotômetro UV-Vis a $765 \mathrm{~nm}$, em triplicata. Os resultados foram expressos em mg de equivalente de ácido gálico por 100 gramas de amostra (mg EAG $100 \mathrm{~g}^{-1}$ ).

\subsection{Atividade antioxidante}

O ensaio foi realizado pelo método de microdiluição em microplacas de 96 poços para obter a economia de reagentes, conforme Mezza et al. (2018) com adaptações. Para cada poço da microplaca, adicionou-se $100 \mu \mathrm{L}$ de 2,2-difenil-1picrilhidrazil (DPPH) em metanol, além de serem misturados com $100 \mu \mathrm{L}$ de OE nas concentrações 5; 2,5; 1,25; 0,625; 0,3125 e $0,15625 \mathrm{mg} \mathrm{mL}^{-1} \mathrm{em}$ metanol. $\mathrm{O}$ sistema foi mantido em repouso no escuro por 2 horas e em seguida, submetidos à leitura em espectrofotômetro de microplacas (VersaMax Tunable ${ }^{\mathrm{TM}}$ - Molecular Devices - Sunnyvale, CA, EUA) a 517 nm. Abaixo está representando a equação da capacidade percentual de eliminação do radical livre: 


$$
\text { Atividade antioxidante } \%=\frac{A C-A S}{A C} * 100
$$

ONDE: AC é a absorbância da solução de controle, e AS é a absorbância da solução de amostra contendo OE antioxidante.

\subsection{Atividade bactericida}

Foi utilizado cepa bacteriana de S. aureus (ATCC 25923) e um isolado de E. coli (O157: H7) cedidas pelo laboratório de Microbiologia do Instituto Federal de Educação, Ciência e Tecnologia de Brasília, Campus Planaltina, Distrito Federal, Brasil. A cultura em estoque foi armazenada em meio de cultivo $(5 \mathrm{~g}$ de peptona bacteriológica, $3 \mathrm{~g}$ de extrato de carne e $1 \mathrm{~L}$ de água destilada). Para reativação das bactérias, inoculou-se $100 \mu \mathrm{L}$ em tubos contendo $10 \mathrm{~mL}$ de meio líquido, e incubadas a $37{ }^{\circ} \mathrm{C}$ por 24 horas. Padronizou-se a suspensão bacteriana, onde diluiu em meio líquido até adquirir a turvação da solução equalizado com solução padrão na escala 0,5 McFarland, correspondendo a $1,5 \times 10^{8} \mathrm{UFC} \mathrm{mL}^{-1}$.

No método de difusão em discos, as placas de Petri foram primeiramente esterilizadas e preparadas com meio Ágar nutriente (5 g de peptona bacteriológica, $3 \mathrm{~g}$ de extrato de carne, $25 \mathrm{~g}$ de ágar e $1 \mathrm{~L}$ de água destilada). Em seguida, após a

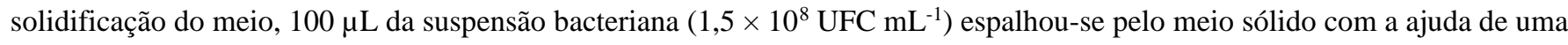
alça de Drigalski na superfície de toda a placa. Logo, os discos de papel filtro de $6 \mathrm{~mm}$ foram mergulhados nas soluções de $\mathrm{OE}$ das folhas de $O$. basilicum e $O$. gratissimum em diferentes concentrações $\left(0,6 ; 0,3 ; 0,15 ; 0,075 ; 0,037\right.$ e $\left.0,018 \mathrm{mg} \mathrm{mL}^{-1}\right) \mathrm{em}$ DMSO e com isso, colocados sobre o meio de cultura e mantidos em estufa bacteriológica a $37{ }^{\circ} \mathrm{C}$ por 24 horas. Para analisar a atividade bactericida determinou-se em termos em diâmetro (mm) do halo de inibição de crescimento.

Para determinar a concentração inibitória mínima (CIM), $150 \mu \mathrm{L}$ das suspenções bacterianas de $S$. aureus e E. coli $\left(1,5 \times 10^{8} \mathrm{UFC}_{\mathrm{mL}^{-1}}\right)$ foram misturadas a $50 \mu \mathrm{L}$ das soluções de $\mathrm{OE}$ das folhas de $O$. basilicum e $O$. gratissimum nas diferentes concentrações em Tween 80 a 1\% (v/v), posteriormente manteve-se em estufa bacteriológica a $37^{\circ} \mathrm{C}$ por 24 horas. Ao término, as amostras foram submetidas à leitura em espectrofotômetro de microplacas (VersaMax Tunable ${ }^{\mathrm{TM}}$ - Molecular Devices Sunnyvale, CA, EUA) em absorbância no comprimento de ondas de $630 \mathrm{~nm}$. Abaixo está representada a equação para taxa de inibição calculada:

$$
\text { Inibição } \%=\frac{A C-A S}{A C} * 100
$$

ONDE: AC é a absorbância da solução de controle e AS é a absorbância da solução de amostra contendo o OE.

\subsection{Análise estatística}

Os experimentos foram realizados em triplicata e o delineamento experimental utilizado, foi inteiramente casualizado. Os dados foram submetidos à análise de variância (ANAVA), e as médias dos tratamentos foram avaliadas por meio do teste de Tukey com 5\% de significância pelo programa SISVAR ${ }^{\circledR}$ (Ferreira, 2011).

\section{Resultados}

Os OEs de $O$. gratissimum e $O$. basilicum apresentaram características organolépticas: aromáticos, translúcidos, com menor densidade em água, com rendimento médio de $0,44 \%$ e $0,38 \%$, respectivamente (Tabela 1 ). 
Tabela 1. Rendimento expresso em percentual de óleo essencial para Ocimum gratissimum e Ocimum basilicum.

\begin{tabular}{lcccc}
\hline \multicolumn{2}{c}{ O. gratissimum } & \multicolumn{2}{c}{ O. basilicum } \\
\hline $\begin{array}{l}\text { Tempo de } \\
\text { Extração/Período }\end{array}$ & Manhã & Tarde & Manhã & Tarde \\
\hline $\mathbf{2}$ horas & $0,41 \pm 0,1$ & $0,35 \pm 0,01$ & - & - \\
$\mathbf{4}$ horas & $0,44 \pm 0,1$ & $0,36 \pm 0,04$ & $0,05 \pm 0,01$ & $0,38 \pm 0,03$ \\
\hline
\end{tabular}

(-) não determinado. Fonte: Autores (2021).

O perfil químico dos OEs, os índices de retenção linear em função do tempo de extração e horário de coleta do material foliar de O. gratissimum e O. basilicum estão apresentados na (Tabela 2). Os compostos majoritários de $O$. gratissimum foi eugenol e eucaliptol, sendo o maior rendimento de eugenol $89 \%$ com as folhas coletadas no período da tarde, e de eucaliptol 9\% para as folhas coletadas no período da manhã com quatro horas de extração. Os compostos majoritários do OE de $O$. basilicum foi eugenol, $\beta$-linalool e muurolol, sendo o maior rendimento para eugenol $74 \%$ nas plantas coletadas no período da tarde e de $\beta$-linalool 16\% e muurolol 6\% nas plantas coletadas pela manhã, ambos com 4 horas de extração.

Tabela 2. Perfil químico por CG-EM dos óleos essenciais das folhas de Ocimum gratissimum e Ocimum basilicum variando tempo de extração versus período do dia coletadas.

\begin{tabular}{|c|c|c|c|c|c|c|}
\hline \multirow[b]{2}{*}{ Compostos } & \multicolumn{6}{|c|}{ Óleo essencial foliar de $O$. gratissimum } \\
\hline & $\mathbf{I}_{\text {Ret Lit }}$ & $\mathbf{I}_{\text {Ret Cal }}$ & $\begin{array}{c}\text { Tempo } \\
\text { 2h/M }\end{array}$ & $\begin{array}{c}\text { Tempo } \\
\text { 4h/M }\end{array}$ & $\begin{array}{c}\text { Tempo } \\
\text { 2h/T }\end{array}$ & $\begin{array}{c}\text { Tempo } \\
4 \mathrm{~h} / \mathrm{T} \\
\end{array}$ \\
\hline Eucaliptol & 1014 & 1031 & 7,89 & 9,60 & 6,64 & 5,14 \\
\hline$\beta$-Trans-ocimeno & 1037 & 1036 & 0,37 & 0,85 & 0,27 & 0,27 \\
\hline$\beta$-linalool & 1135 & 1101 & 0,09 & 0,24 & 0,27 & 0,27 \\
\hline$\alpha$-terpineol & 1188 & 1192 & 0,23 & 0,30 & 0,44 & 0,44 \\
\hline Eugenol & 1359 & 1362 & 88,44 & 83,31 & 89,54 & 89,54 \\
\hline$\beta$-cariofileno & 1423 & 1421 & 0,77 & 2,17 & 1,06 & 1,06 \\
\hline D-germacreno & 1485 & 1482 & 0,51 & 0,84 & 0,63 & 0,63 \\
\hline$\beta$-selineno & 1490 & 1488 & 1,43 & 1,97 & 1,94 & 1,94 \\
\hline$\alpha$-guaieno & 1493 & 1497 & 0,27 & 0,72 & 0,71 & 0,71 \\
\hline \multirow[b]{2}{*}{ Compostos } & \multicolumn{6}{|c|}{ Óleo essencial foliar de $O$. basilicum } \\
\hline & $\mathbf{I}_{\text {Ret Lit }}$ & $\mathbf{I}_{\text {Ret Cal }}$ & \multicolumn{2}{|c|}{$\begin{array}{c}\text { Tempo } \\
\text { 4h/M }\end{array}$} & \multicolumn{2}{|c|}{$\begin{array}{c}\text { Tempo } \\
4 \mathrm{~h} / \mathrm{T}\end{array}$} \\
\hline Eucaliptol & 1014 & 1031 & \multicolumn{2}{|c|}{0,81} & \multicolumn{2}{|c|}{0,74} \\
\hline$\beta$-linalool & 1135 & 1101 & \multicolumn{2}{|c|}{16,03} & \multicolumn{2}{|c|}{14,81} \\
\hline$\alpha$-terpineol & 1188 & 1192 & \multicolumn{2}{|c|}{0,47} & \multicolumn{2}{|c|}{0,32} \\
\hline Bornil acetato & 1288 & 1287 & \multicolumn{2}{|c|}{0,54} & \multicolumn{2}{|c|}{0,45} \\
\hline Eugenol & 1359 & 1361 & \multicolumn{2}{|c|}{72,32} & \multicolumn{2}{|c|}{74,52} \\
\hline$\alpha$-bergamoteno & 1434 & 1437 & \multicolumn{2}{|c|}{1,22} & \multicolumn{2}{|c|}{1,07} \\
\hline D-germacreno & 1485 & 1498 & \multicolumn{2}{|c|}{0,24} & \multicolumn{2}{|c|}{0,24} \\
\hline$\gamma$-cadieno & 1513 & 1516 & \multicolumn{2}{|c|}{0,88} & \multicolumn{2}{|c|}{0,62} \\
\hline Cubenol & 1619 & 1618 & \multicolumn{2}{|c|}{0,71} & \multicolumn{2}{|c|}{0,49} \\
\hline Muurolol & 1646 & 1644 & \multicolumn{2}{|c|}{6,76} & \multicolumn{2}{|c|}{6,55} \\
\hline
\end{tabular}

$\mathrm{I}_{\text {Ret Lit }}=$ Índice de Retenção Literatura (ADAMS, 2007), $\mathrm{I}_{\text {Ret cal }}=$ Índice de Retenção Calculado usando a equação de Van den Dool e Kratz; $\mathrm{M}=$ manhã, $\mathrm{T}=$ tarde. Fonte: Autores (2021).

Na Tabela 3 estão apresentados os resultados para compostos fenólicos totais avaliados nos OEs foliares de $O$. gratissimum e O. basilicum. O teor de compostos fenólico totais dos OEs de O. gratissimum e O. basilicum foi $=17$ e $16 \mathrm{mg}$ de EAG $100 \mathrm{~g}^{-1}$ respectivamente, não apresentando diferença significativa conforme teste de Tukey com (p $\left.\leq 0,05\right)$ de probabilidade. 
Tabela 3. Teor de compostos fenólico totais dos óleos essenciais de Ocimum gratissimum e Ocimum basilicum.

\begin{tabular}{lc}
\hline Óleo essencial & $\begin{array}{c}\text { *Teor de fenólicos totais } \\
\text { em mg de EAG } \mathbf{1 0 0} \mathbf{~ g}^{\mathbf{- 1}}\end{array}$ \\
\hline O. gratissimum & $17,90 \pm 0,75 \mathrm{a}$ \\
O. basilicum & $16,44 \pm 0,69 \mathrm{a}$ \\
\hline
\end{tabular}

* EAG equivalente de ácido gálico por $100 \mathrm{~g}^{-1}$, em base óleo essencial. Médias seguidas de mesma letra na coluna não diferem significativamente pelo teste de Tukey ( $\leq$ 0,05). Fonte: Autores.

Os resultados para atividade antioxidante dos OEs de O. gratissimum e O. basilicum estão apresentados na (Figura 1). A atividade antioxidante do OE de O. gratissimum foi de $100 \%$ de sequestro do radical livre 2,2-difenil-1-picrilhidrazil (DPPH) nas três maiores concentrações de $\left(15,6 ; 7,8\right.$ e $\left.3,9 \mu \mathrm{g} \mathrm{mL} \mathrm{m}^{-1}\right)$. Para o $\mathrm{OE}$ de $O$. basilicum a atividade antioxidante variou entre 100 a $77 \%$ nas mesmas concentrações.

Figura 1. Atividade antioxidante pela redução do radical livre DPPH avaliado nos óleos essenciais foliares de Ocimum gratissimum e Ocimum basilicum.

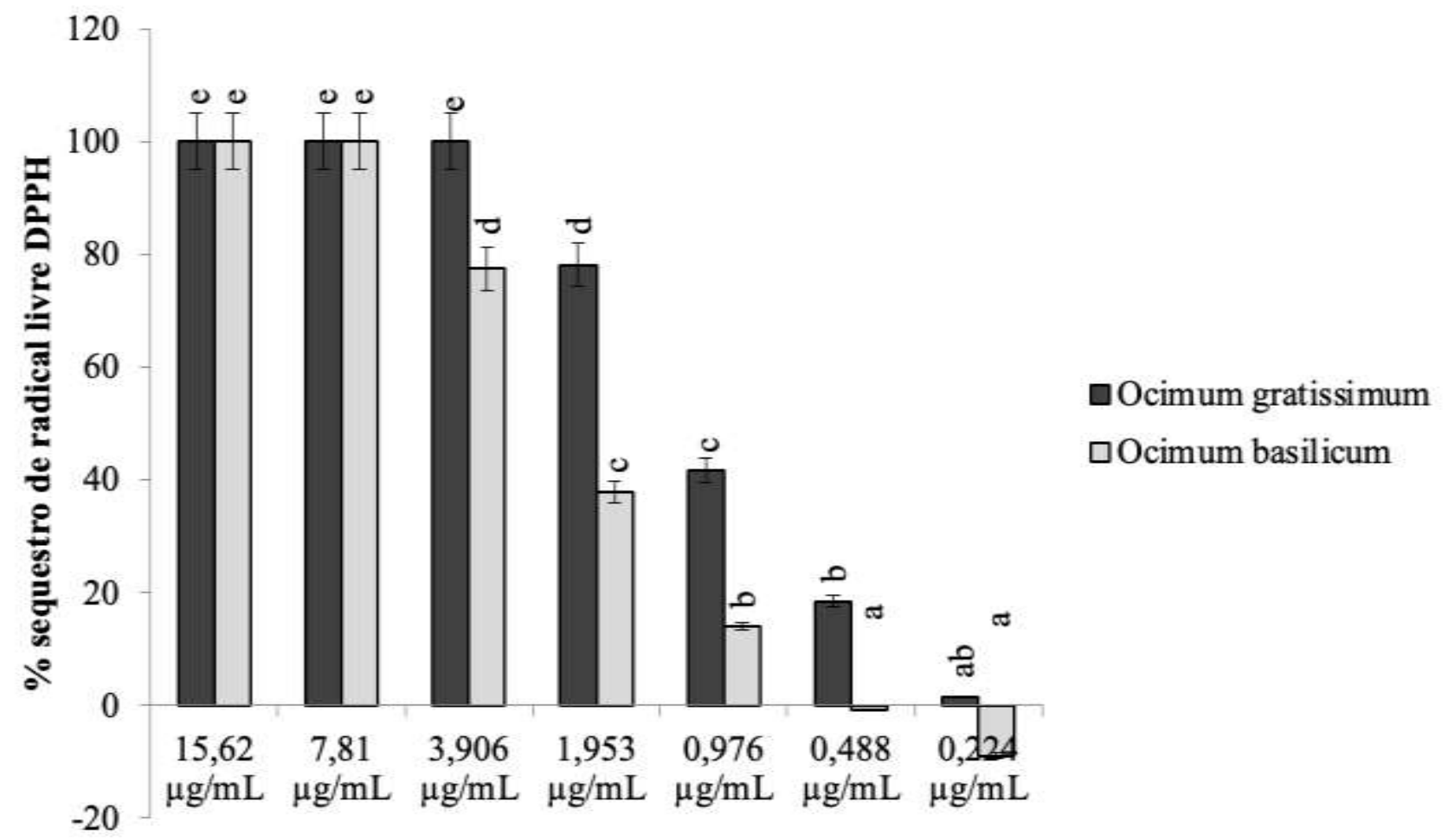

Letras diferentes para concentração e óleo essencial da mesma espécie não diferem significativamente pelo teste de Tukey ( $\mathrm{p} \leq 0,05)$. Fonte: Autores (2021).

Os resultados do teste de difusão em discos e os halos de inibição de crescimento bacteriano causados pelos OEs de O. gratissimum e O. basilicum, estão representados na (Figura 2 e 3). Os OEs de O. gratissimum e O. basilicum apresentaram halos de inibição sobre o isolado de $E$. coli $=11$ e $7 \mathrm{~mm}$, respectivamente (Figura 2). 
Figura 2. Comparação entre as medidas dos diâmetros dos halos de inibição do crescimento microbiano (mm) do isolado de Escherichia coli obtidas utilizando os óleos essenciais de Ocimum gratissimum e Ocimum basilicum.

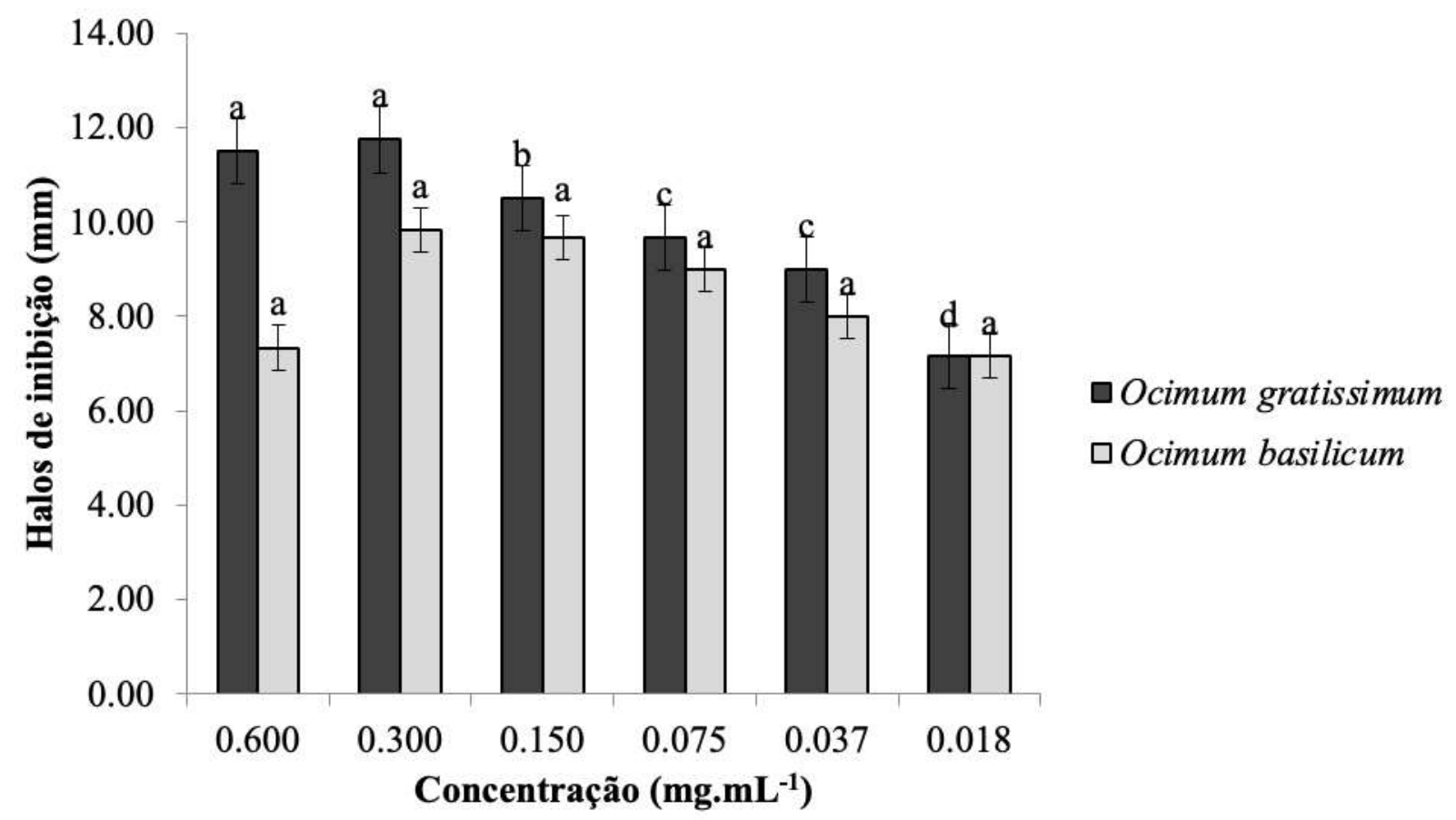

Letras diferentes para concentração e óleo essencial da mesma espécie não diferem significativamente pelo teste de Tukey ( $\mathrm{p} \leq 0,05)$. Fonte: Autores (2021).

Os halos de inibição dos OEs de O. gratissimum e O. basilicum sobre a cepa de S. aureus $=9$ e $10 \mathrm{~mm}$, respectivamente (Figura 3).

Figura 3. Comparação entre as medidas dos diâmetros dos halos de inibição do crescimento microbiano em (mm) da cepa de Staphylococcus aureus obtidas utilizando os óleos essenciais de Ocimum gratissimum e Ocimum basilicum.

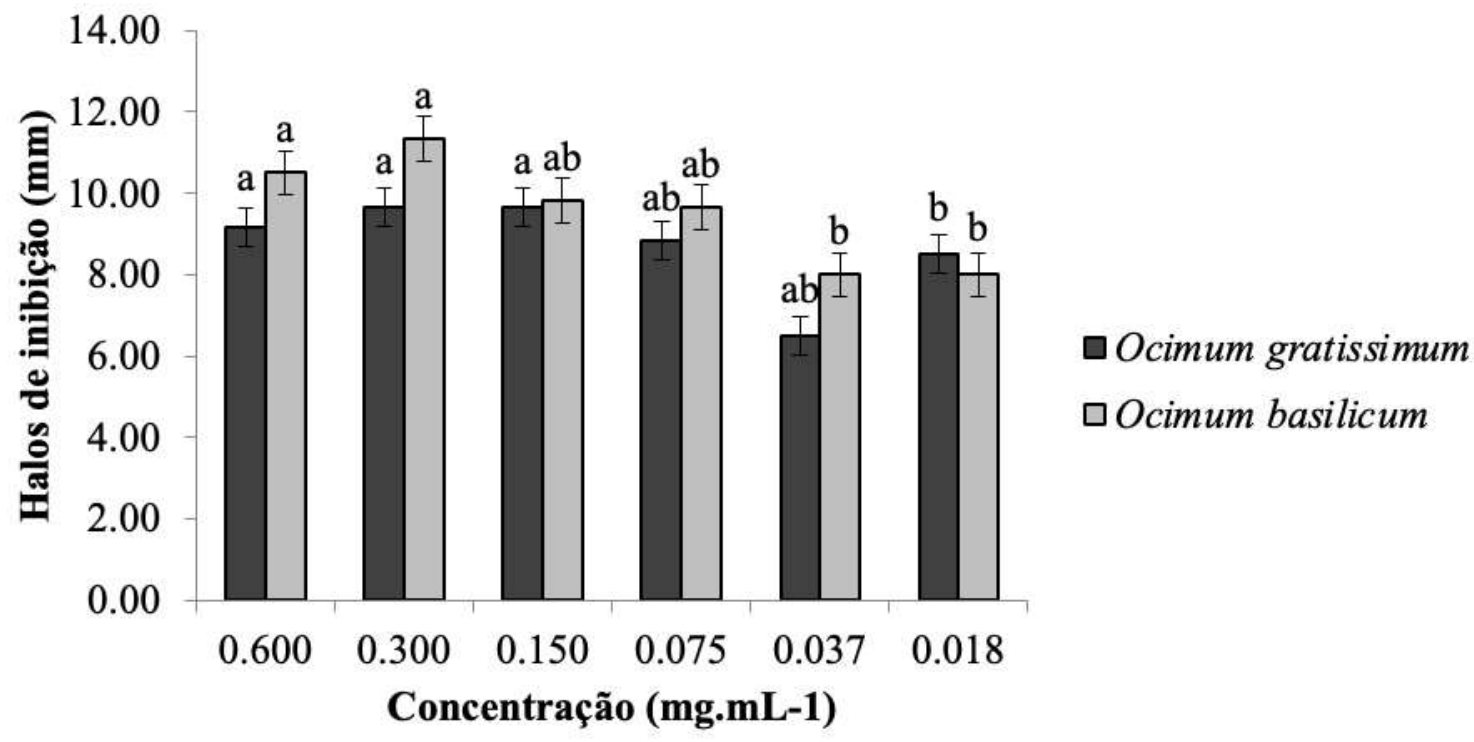

Letras diferentes para concentração e óleo essencial da mesma espécie não diferem significativamente pelo teste de Tukey ( $\mathrm{p} \leq 0,05)$. Fonte: Autores (2021). 
Estão apresentados na Tabela 4, os resultados da avaliação da atividade bactericida pelo método de diluição em caldo dos OEs foliares de $O$. gratissimum e $O$. basilicum sobre a cepa de $S$. aureus e o isolado de $E$. coli. A atividade bactericida do OE de $O$. gratissimum sobre o isolado de E. coli variou entre 100 e $38 \%$ de inibição do crescimento microbiano para as maiores e menores concentrações $\left(0,6-0,018 \mathrm{mg} \mathrm{mL}^{-1}\right)$, enquanto que sobre a cepa de $S$. aureus a atividade bactericida variou entre 100 e $15 \%$ de inibição do crescimento microbiano nas mesmas concentrações (Tabela 4).

A inibição do crescimento microbiano do isolado de E. coli pelo OE de $O$. basilicum variou entre 66 e $21 \%$ para as maiores e menores concentrações $\left(0,6-0,018 \mathrm{mg} \mathrm{mL}^{-1}\right)$. Sobre a cepa de $S$. aureus apresentou inibição do crescimento micelial onde variou entre 83 a 2\%, nas respectivas concentrações (Tabela 4).

Tabela 4. Avaliação da atividade bactericida dos óleos essenciais foliares de Ocimum gratissimum e Ocimum basilicum o isolado Escherichia coli e a cepa de Staphylococcus aureus.

\begin{tabular}{|c|c|c|}
\hline \multirow{2}{*}{$\begin{array}{l}\text { Concentração } \\
\left(\mathrm{mg} \mathrm{mL}^{-1}\right)\end{array}$} & \multicolumn{2}{|c|}{ Inibição de Escherichia coli (\%) } \\
\hline & O. gratissimum & O. basilicum \\
\hline 0,600 & $100,00 \mathrm{a}$ & $66,23 \mathrm{~b}$ \\
\hline 0,300 & $64,98 \mathrm{~b}$ & $57,08 \mathrm{~d}$ \\
\hline 0,150 & $60,50 \mathrm{c}$ & $47,73 \mathrm{f}$ \\
\hline 0,075 & $53,92 \mathrm{e}$ & $37,99 \mathrm{~g}$ \\
\hline 0,037 & $47,08 \mathrm{f}$ & $33,17 \mathrm{~h}$ \\
\hline 0,018 & $38,06 \mathrm{~g}$ & $21,74 \mathrm{i}$ \\
\hline CIM & 0,14 & 0,31 \\
\hline \multirow{2}{*}{$\begin{array}{l}\text { Concentração } \\
\left(\mathrm{mg} \mathrm{mL}^{-1}\right)\end{array}$} & \multicolumn{2}{|c|}{ Inibição de Staphylococcus aureus (\%) } \\
\hline & O. gratissimum & O. basilicum \\
\hline 0,600 & $100,00 \mathrm{a}$ & $83,67 \mathrm{~b}$ \\
\hline 0,300 & $43,58 \mathrm{c}$ & $33,61 \mathrm{~d}$ \\
\hline 0,150 & $31,70 \mathrm{~d}$ & $23,91 \mathrm{e}$ \\
\hline 0,075 & $25,87 \mathrm{e}$ & $14,41 \mathrm{f}$ \\
\hline 0,037 & $24,57 \mathrm{e}$ & $7,32 \mathrm{~g}$ \\
\hline 0,018 & $15,67 \mathrm{f}$ & $2,53 \mathrm{~h}$ \\
\hline CIM & 0,27 & 0,36 \\
\hline
\end{tabular}

Médias seguidas por letras iguais nas linhas e colunas separadas por cepas não diferem significativamente pelo teste de Tukey a $(\mathrm{p} \leq 0,05)$; CIM: Concentração inibitória mínima $\mathrm{mg} \mathrm{mL}^{-1}$. Fonte: Autores.

\section{Discussão}

As análises por cromatografia gasosa acoplada à espectrometria de massas identificaram em ambos os OEs de $O$. gratissimum e $O$. basilicum nove e 10 compostos voláteis, respectivamente. Já no estudo realizado por Dris et al. (2017) para O. basilicum, os pesquisadores encontraram cerca de 38 compostos. O composto majoritário neste estudo para $O$. gratissimum foi o eugenol com $88 \%(2 \mathrm{~h} / \mathrm{M}), 83 \%(4 \mathrm{~h} / \mathrm{M}), 89 \%(2 \mathrm{~h} / \mathrm{T})$ e $89 \%(4 \mathrm{~h} / \mathrm{T})$, e para $O$. basilicum eugenol com $72 \%(4 \mathrm{~h} / \mathrm{M}), 74 \%$ (4h/T), $\beta$-linalool com 16\% (4h/M), 14\% (4h/T) e para muurolol 6\% (4h/M) e 6\% (4h/T).

O tempo influenciou no quantitativo de eugenol em O. gratissimum para 2 e 4 horas de extração nos períodos da manhã e tarde, o mesmo não foi observado para 2 e 4 horas no período da tarde que se manteve resultados iguais. Já para os compostos linalool, eugenol e muurolol tanto para 4 horas de extração no período da manhã quanto da tarde houve diferença do quantitativo detectado para $O$. basilicum (Tabela 1).

Comparando os resultados desse trabalho com outros estudos, verificaram-se similaridades na composição química dos OEs de $O$. gratissimum e $O$. basilicum identificados nesta pesquisa. O trabalho realizado por Chimnoi et al. (2018) encontraram para o OE de O. gratissimum os seguintes compostos majoritários, eugenol 55,6\%, Cis-ocimeno 13,9\%, $\gamma$ muuroleno 11,6\%, (Z,E)- $\alpha$-farneseno 5,6\%, $\alpha$-Trans-bergamoteno 4,1\% e $\beta$-cariofileno 2,7\%. Já Luz et al. (2009) avaliando os 
constituintes químicos dos OEs de dois genótipos de $O$. basilicum encontraram os seguintes compostos 1,8-cineol 2,3\% e $4,5 \%$, linalool 60,5\% e 64,0\%, geraniol $9,0 \%$ e $8,2 \%$, calareno $1,7 \%$ e $2,8 \%$ e D-germacreno $2,9 \%$ e 3,8\%. Entretanto, no presente estudo não foram detectados os compostos, bornil acetato, $\alpha$-bergamoteno, $\gamma$-cadieno, cubenol e muurolol no OE de $O$. gratissimum e para $O$. basilicum $\beta$-Trans-ocimeno, $\beta$-cariofileno, $\beta$-selineno e $\alpha$-guaieno.

O conteúdo de fenólicos totais não apresentou diferença significativa entre os OEs de $O$. gratissimum e $O$. basilicum onde apresentaram quantitativos fenólicos com alta expressividade (Tabela 2). Nota-se que a presença de compostos fenólicos pode variar entre os OEs de vários táxons vegetais, alguns podem apresentar taxa de detecção muito baixa como observado por Stiven et al. (2009) onde avaliaram OEs de Eugenia pyriformis onde o quantitativo ficou abaixo do nível de quantificação de 5 $\mu \mathrm{g} \mathrm{mL}{ }^{-1}$; ou não apresentarem como observado no estudo desenvolvido por Hossain et al. (2011) avaliando o OE de Merremia borneensis, e no OE de Tetrastigma no estudo desenvolvido por Hossain; Shah (2015). As quantidades de compostos fenólicos em ambos os OEs avaliados, podem contribuir para atividade antioxidante destes EOs.

$\mathrm{Na}$ atividade antioxidante, os OEs de $O$. gratissimum e $O$. basilicum apresentaram 100\% de redução do radical DPPH nas maiores concentrações avaliadas (Figura 2). Para as menores concentrações 0,488 e $0,224 \mu \mathrm{g} \mathrm{mL}^{-1}$ não houve atividade de inibição dos OEs nesta pesquisa. Os resultados deste estudo quanto à atividade antioxidante se mostraram promissores quando comparados com outros estudos realizados por Silvestre et al. (2010) onde obtiveram maior atividade antioxidante de 95,6\% na concentração de $10000 \mu \mathrm{g} \mathrm{mL}^{-1}$ e menor atividade antioxidante de $44,1 \%$ na concentração de $150 \mu \mathrm{g} \mathrm{mL}^{-1}$ para o OE de Eugenia caryophyllata. A redução do antioxidante DPPH se deve a composição química dos OEs ricos em compostos fenólicos como o eugenol que possui atividade antioxidante reconhecida (LEE et al., 2005).

Substâncias antioxidantes são aquelas capazes de impedir ou retardar a oxidação de um material oxidável (AMORATI et al., 2013). Neste caso, compostos fenólicos são moléculas capazes de agir como antioxidantes pela doação de hidrogênio do polifenol inibindo a produção do radical causador de processos oxidativos (SAHARI \& BERENJI, 2015). Os estudos de Amorati et al. (2013) e Torres-Martinez et al. (2017), confirmam esses dados através da avaliação da atividade antioxidante dos OEs de Satureja macrostema e seus compostos majoritários isoladamente, verificando que os compostos fenólicos timol, linalool e carvacrol eram os responsáveis pela atividade antioxidante. No entanto, segundo Xu et al. (2017) a atividade antioxidante não se deve apenas pelos compostos majoritários, mas sim pelo conjunto de compostos em diferentes concentrações, agindo como sinergismo.

O ensaio bactericida apresentou inibição do crescimento microbiano de 100 e $66 \%$ para E. coli e de 100 e $83 \%$ para $S$. aureus na maior concentração $\left(0,600 \mathrm{mg} \mathrm{mL}^{-1}\right)$ e na menor concentração $\left(0,018 \mathrm{mg} \mathrm{mL}^{-1}\right)$ a inibição do crescimento microbiano foi de 38 a $21 \%$ para E. coli e de 15 a $2 \%$ para $S$. aureus sobre os OEs de O. gratissimum e O. basilicum respectivamente (Tabela 3). Pode-se inferir que a presença do eugenol em ambos os OEs de $O$. gratissimum e $O$. basilicum também apresentou potencial bactericida.

Comparando com o estudo realizado por Pombo et al. (2018) a bactéria Gram-negativa E. coli demonstrou resistência em todas as concentrações avaliadas, já para a bactéria Gram-positiva $S$. aureus apresentaram maior susceptibilidade de inibição aos OEs de cravo e orégano. Neste estudo, os resultados avaliando os OEs de O. gratissimum e O. basilicum apresentaram halos de inibição entre 10 e $12 \mathrm{~mm}$, respectivamente, para E. coli e halos de inibição entre 9 e $11 \mathrm{~mm}$ respectivamente, para S. aureus.

Resultados ainda mais promissores foram observados neste trabalho utilizando método de diluição em caldo com CIM $=0,14$ e $0,31 \mathrm{mg} \mathrm{mL}^{-1}$ sobre E. coli e 0,27 e $0,36 \mathrm{mg} \mathrm{mL}^{-1}$ sobre $S$. aureus, pelos OEs de $O$. gratissimum e $O$. basilicum, respectivamente. Em comparação com outros trabalhos, o $\mathrm{OE}$ de $O$. basilicum apresentou atividade bactericida sobre bactérias E. coli e $S$. aureus, com CIM =0,25 a 1,00 $\mathrm{mg} \mathrm{g}^{-1}$ (GAIO et al., 2015). O OE de $O$. gratissimum também apresentou resultado 
promissor no controle microbiano de $S$. aureus $\mathrm{CIM}=0,03 \mathrm{mg} \mathrm{mL}^{-1}$, Salmonella choleraesuis e E. coli ambas com CIM $=1,0$ $\mathrm{mg} \mathrm{mL} \mathrm{m}^{-1} \mathrm{e}$ Listeria innосиа $\mathrm{CIM}=2,0 \mathrm{mg} \mathrm{mL}^{-1}$, conforme reportado por Granados et al. (2018).

Os compostos eugenol e eucaliptol encontrado no OE de O. gratissimum, e eugenol, $\beta$-linalool e muurolol no $\mathrm{OE}$ de O. basilicum possuem atividade antimicrobiana comprovada. De acordo com Murari et al. (2008) e Xu et al. (2017) os OEs isolados ou em combinação podem potencializar a ação bactericida havendo sinergismo positivo, onde vários compostos se combinam promovendo maior inibição do agente patológico. Adicionalmente, Granados et al. (2018) também identificaram eugenol $=66,4 \%$ entre os compostos majoritários presentes no $\mathrm{OE}$ de $O$. gratissimum, assim como no presente estudo, destacando o potencial biotecnológico deste $\mathrm{OE}$ e seus compostos químicos.

Adicionalmente, o mecanismo de ação do OE de Enteromorpha linza L. sobre E. coli, está relacionado ao aumento da condutividade elétrica, alteração da morfologia bacteriana, redução da viabilidade celular, rompimento celular e vazamento dos íns de $\mathrm{K}^{+}$após 6 horas de incubação (Patra et al., 2015). Por esse motivo, os OEs são bons candidatos no controle de microrganismos devido ao caráter lipofílico de seus compostos químicos, o que facilita sua permeabilidade na célula, lise e morte celular (Kotzekidou et al., 2008).

Nesse sentido, os resultados deste estudo sugerem que os OEs de $O$. gratissimum e $O$. basilicum apresentam atividade bactericida sobre E. coli e $S$. aureus, microrganismo causadores de intoxicações alimentares, podendo atuar como antioxidante e antimicrobiano natural. Ademais, mais estudos são necessários para determinar as concentrações ideais do OE, seus aspectos toxicológicos, tecnológicos e sensoriais a serem explorados pela indústria de alimentos.

\section{Conclusão}

O horário e tempo de extração influenciaram no rendimento de óleo essencial, bem como nas variações de proporção dos compostos químicos majoritários. Quanto à composição química, os óleos essenciais de $O$. gratissimum e $O$. basilicum apresentaram o eugenol entre os compostos majoritários. Adicionalmente, os resultados obtidos em nosso trabalho demonstraram quantidades de fenóis significativos para ambos os óleos essenciais avaliados, podendo apresentar importante ação antioxidante.

Os óleos essenciais de $O$. gratissimum e $O$. basilicum apresentaram boa atividade antioxidante no sequestro do radical livre DPPH, nas maiores concentrações avaliadas. Quanto a atividade bactericida frente as cepas de E. coli e S. aureus, o óleo essencial de $O$. gratissimum apresentou maior potencial inibidor que o óleo essencial de $O$. basilicum, nas concentrações avaliadas. Nesse sentido, pode-se concluir que os óleos essenciais de $O$. gratissimum e $O$. basilicum possuem ação antioxidante e bactericida, nas condições avaliadas, e seu potencial biotecnológico pode ser uma excelente alternativa a serem utilizados pela indústria alimentícia ou farmacêutica.

\section{Agradecimentos}

Os autores agradecem à Faculdade de Iporá (FAI), à Universidade Federal de Goiás (UFG), ao Instituto Federal de Educação, Ciência e Tecnologia Goiano (IF Goiano), ao Instituto Federal de Educação, Ciência e Tecnologia de Barbacena e à Universidade Federal de São Carlos (UFSCAR) pelo apoio; e aos órgãos de fomento em pesquisa CAPES, CNPq, FINEP.

\section{Referências}

Abe, H., Carneiro, P., Chagas, E., Chaves, F., Couto, M., Cunha, F., Fujimoto, R., Maria, A., Martins, M., Ramos, F., Sousa, N. (2018). Efficacy of Ocimum gratissimum essential oil against the monogenean Cichlidogyrus tilapiae gill parasite of Nile tilapia. Arq. Bras. Med. Vet. Zootec., v.70, n.2, p.497-504.

Abdou, A. M.; Higashigychi, S.; Aboueleinin, A. M.; Kim, M.; Ibraim, H. R. (2007). Antimicrobial peptides derived from hen egg lysozyme with inhibitory effect againt Bacillus species. Food Control. 18:173-8. 
Adams, R. P. (1995). Identification of essential oil components by Gas Chromatography/Mass spectroscopy. Allured Publishing Corporation: Illinois USA, p. 456.

Affini, R., Bernadi, A., Boeck, E., Lunardi, N., Mangetti, M., Neto, R., Oliveira, G. (2017). In situ evaluation of Basil essential oil cytotoxicity (Ocimum basilicum L.). Journal of Research in Dentistry.

Alali, W. Q., Hofacre, C. L., Mathis, G. F., Faltys, L. (2013). Effect of essential oil compound on shedding and colonization of Salmonella enterica serovar Heidelberg in broilers. Poult Sci., 92(3): 836-41.

Alves, J. A. B., Alves, P. B., Aquino, L. C. L., Blank, A. F., Carvalho, L. M., Santos, G. G., Santos, P. O., Trindade, R. C. (2010) Atividade antimicrobiana dos óleos essenciais de erva-cideira e manjericão frente a bactérias de carnes bovinas. v. 21, n. 4, p. 529-535.

Amaral, F. (2016). Técnicas de Aplicação de Óleos Essenciais - Terapias de Saúde e Beleza. Cengage Learning. p. 128.

Amiri, H. (2012). Essential Oils Composition and Antioxidant Properties of Three Thymus Species. Evidence-Based Complementary and Alternative Medicine.

Amorati, R., Foti, M. C., Valgimigli, L. (2013). Antioxidant Activity of Essential Oils. J. Agric. Food Chem., 61, 10835-10847.

Araujo, E. T. H., Costa, A. C., Ferreira, K. L. C., Junior, E. C., Pereira, E. M., Silva, K. M. R. (2018). Avaliação da ação antimicrobiana do látex de mangabeira em duas cepas de bactérias causadoras de pneumonia. Revista de prevenção de infecção e saúde

Baldin, E. L. L., Pereira, J. M. (2010). Resistência de Génótipos de feijoeiro a Zabrotes subfasciatus (Coleoptera: Bruchidae). Ciênc. agrotec., v. 34, n. 6, p. 1507-1513.

Benjamaa, M., Neves, M. A., Falleh, H., Isoda, H., Ksouri, R., Nakajima, M. (2018). Nanoencapsulation of Thymus capitatus essential oil: Formulation process, physical stability characterization and antibacterial efficiency monitoring. Industrial Crops \& Products 113, 414-421.

Bezerra, S., Cruz, M. (2017). Obtenção do óleo essencial de Ocimum gratissimum L para desenvolvimento de cosmético de limpeza facial. Revista Diálogos Acadêmicos, Fortaleza, v. 6, n. 2.

Bizzo, H. R., Rovell, A. M. C., Rezende, C. M. (2009). Óleos essenciais no Brasil: aspectos gerais, desenvolvimento e perspectivas. Química Nova, v.32, n.3, p. 7.

Blank, A. F., Luz, J. M. Q., Morais, T. P. S., Oliveira, G. S., Sodré, A. C. B. (2009). Teor, rendimento e composição química do óleo essencial de manjericão sob doses de cama de frango. Horticultura Brasileira, v. 27, n. 3.

Bouyahya, A., Et-Touys, A., Abrini, J., Talbaqui, A., Fellah, H., Bakri, Y., Dakka, N. (2017). Lavandula stoechas essential oil from Morocco as novel source of antileishmanial, antibacterial and antioxidant activities. Biocatalysis and Agricultural Biotechnology, 12, 179-184.

Câmera, C. A. G., Coitinho, R. L. B. C., Junior, M. G. C. G., Oliveira, J. V. (2006). Atividade inseticida de óleos vegetais sobre Sitophilus zeamais Mots. (Coleoptera: Curculionidae) em milho armazenado. Revista Caatinga, v.19, n.2, p. 176-182.

Colombare, L. F., Echer, M. M., Favorito, P. A., Offemann, L.C., Hachmann, T. L., Schlindwein, M. D., Schineider, R. P. (2011). Características produtivas do manjericão (Ocimum basilicum L.) em função do espaçamento entre plantas e entre linhas. Revista Brasileira, v.13, p.582-586.

Correa, J. C. R., Salgado, H. R. N. (2011). Atividade inseticida das plantas e aplicações: revisão. Rev. Bras. Pl. Med., v.13, n.4, p.500-506.

Chimnoi N., Reuk-Ngam N., Chuysinuan P., Khlaychan P., Khunnawutmanotham N., Chokchaichamnankit D., Thamniyom W., Klayraung S., Mahidol C., Techasakul S. (2018). Characterization of essential oil from Ocimum gratissimum leaves: Antibacterial and mode of action against selected gastroenteritis pathogens. Microb Pathog, 118: 290-300.

Chópite, M., León, N., González, D., Ulacio, D. (2012). Efecto del extracto etanólico de albahaca genovesa (Ocimum basilicum var. Genovese) sobre Cercospora apii Fressen y el tizón temprano del celery (Apium graveolens). Revista Científica UDO Agrícola 12 (2): 472-478.

Dris D., Tine-Djebbar F., Bouabida H., Soltani N. (2017). Chemical composition and activity of an Ocimum basilicum essential oil on Culex pipiens larvae: Toxicological, biometrical and biochemical aspects. South African Journal of Botany, 113: 362-69.

FDA - U. S. Food \& Drug Administration. (2010). National Antimicrobial Resistance Monitoring System—Enteric bacteria (NARMS): 2007 Executive Report. US Department of Health and Human Services, FDA, Rockville, MD.

Ferreira, D. F. (2011). Sisvar: a computer statistical analysis system. Ciência Agrotecnol. 35 (6): 1039-1042.

Ferreira, L., Henrique, V., Nunes, C. (2017). Análise Físico-Química e Antioxidante de Manjericão (Ocimum basilicum L.) Orgânico. Revista Interdisciplinar do Pensamento Científico, v. 3, n. 2 .

Gaio I., Saggiorato, A.G., Treichel, H. Cichoski,A. J., Astolfi V., Cardoso, R. I., Toniazzo G., Valduga E., Paroul N., Cansian.R.L. (2015). Antibacterial activity of basil essential oil (Ocimum basilicum L.) in Italian-type sausage. J. Verbr. Lebensm. 10, 323-329.

Granados A. P. F., Duarte M.C.T., Rodrigues R. (2018). Antimicrobial effect of the Essential Oil from Ocimum gratíssimum. In: 1ST International Congress On Bioactive Compounds And 2nd International Workshop On Bioactive Compounds: Food Design And Health, 2018, Campinas. Anais eletrônicos... Campinas, Galoá, 2018.

Gonçalvez, P. A. S., Werner, H., Debarba, J. F. (2004). Avaliação de biofertilizantes, extratos vegetais e diferentes substâncias alternativas no manejo de tripes em cebola em sistema orgânico. Horticultura Brasileira, v.22, n.3.

Hossain M. A., Shab M. D., Gnanaraj C., Iqbal M. (2011). In vitro total phenolics, flavonoids contents and antioxidant activity of essential oil, various organic extracts from the leaves of tropical medicinal plant Tetrastigma from Sabah. Asian Pacific J of Trop Medc, 717-21. 
Hossain M. A., Shah M. D. (2015). A study on the total phenols content and antioxidant activity of essential oil and different solvente extracts of endemic plant Merremia borneensis. Arabian J of Chem, 2015; 8(1): 66-71.

Junior, J. I. R., Porcópio, S. O., Santos, J. B., Vendramim, J. D. (2003). Bioatividade de diversos pós de origem vegetal em relação a Sitophilus zeamais Mots. (Coleoptera: Curculionidae). Ciênc. agrotec., v.27, n.6, p.1231-1236.

Lee, S. J., Umano, K., Shibamoto, T., Lee, K. G. (2005). Identification of volatile components in basil (Ocimum basilicum L.) and thyme leaves (Thymus vulgaris L.) and their antioxidant properties. Food Chemistry, 91: 131-37.

Lorenzi, H; Matos, F. J. A. (2002). Plantas Medicinais no Brasil nativas e exóticas. São Paulo: Nova Odessa. 253-254p.

Luz, J. M. Q., Morais, T. P. S., Blank, A. F., Sodré, A. C. B., Oliveira, G. S. (2009). Teor, rendimento e Composição quimica do óleo esencial de manjericão sob doses de cama de frango. Rev Hortic Bras; 27(3): 349-53.

Melo, E. A., Maciel, M. I. S., Araujo, C. R., Lima, V. L. A. G. (2008). Teor de fenólicos totais e capacidade antioxidante de polpas congeladas de frutas. Alim. Nutr., Araraquara, v.19, n.1, p. 67-72.

Mezza, G. N., Borgarello, A. V., Grosso, N. R., Fernandez, H., Pramparo, M. C., Gayol, M. F. (2018). Antioxidant activity of rosemary essential oil fractions obtained by molecular distillation and their effect on oxidative stability of sunflower oil. Food Chemistry 242: 9-15.

Morais, L. A. S. (2009). Influência dos fatores abióticos na composição química dos óleos essenciais. Horticultura Brasileira, v.27, n.2, p.14.

Murari, A. L., Carvalho, F. H., Heinzmann, B. M., Michelot, T. M., Hörner, R., Mallmann, C. A. (2008). Composição e atividade antibacteriana dos óleos essenciais de Senecio crassiflorus var. crassiflorus. Quim Nova, 31(5): 1081-84.

Negi, P. S. (2012). Plant extracts for the control of bacterial growth: Efficacy, stability, and safety issues for food application. International Journal of Food Microbiology. 156:7-17.

Negri, M. L. S., Possamai, J. C., Nakashima, T. (2009). Atividade antioxidante das folhas de espinheira-santa - Maytenus ilicifolia Mart. ex Reiss., secas em diferentes temperaturas. Brazilian Journal of Pharmacognosy, 19(2B): 553-556.

Oh, Y. W., Shahidi, F. (2018). Antioxidant activity of resveratrol ester derivatives in food and biological model systems. Food Chemistry.

Olszowy, M., Dawidowicz, A. L. (2016). Essential oils as antioxidants: their evaluation by DPPH, ABTS, FRAP, CUPRAC, and b-carotene bleaching methods. Monatshefte für Chemie - Chemical Monthly, 147: 12, 2083-2091.

Petretto, G. L., Fancello, F., Bakhy, K., Faiz, C. A. L., Sibawayh, Z., Chessa, M., Zara, S., Sanna, M. L., Maldini, M., Rourke, J. P., Pintore, G. (2018) Chemical composition and antimicrobial activity of essential oils from Cuminum cyminum L. collected in different areas of Morocco. Food Bioscience, 22, 5058 .

Pombo, J. C. P., Ribeiro, E. R., Pinto, R. L., Silva, B. J. M. Efeito antimicrobiano e sinergístico de óleos essenciais sobre bactérias contaminantes de alimentos. Segr Aliment Nutr, 2018; 25(2): 108-17.

Sahari, M. A., Berenji, S. A. (2015). Bio-antioxidants Activity: Their Mechanisms and Measurement Methods. Applied Food Biotechnology, 2(1): 3-8.

Siddique, S., Parveen, Z., Bareen, F., Chaudhary, M. N., Mazhar, S., Nawaz, S. (2017). The essential oil of Melaleuca armillaris (Sol. ex Gaertn.) Sm. leaves from Pakistan: A potential source of eugenol methyl ether. Industrial Crops \& Products, 109, 912-917.

Silvestri, J. D. F., Czyewski, E., Lerin, L., Rotava, L., Cansian, R. L., Mossi, A., Toniazzo, G., Oliveira, D., Treichel, H. Perfil da Composição quimica e atividade antibacteriana e antioxidante do óleo essencial do cravo-da-índia (Eugenia caryophyllata Thumb.). Rev Ceres, 2010; 57(5): 589-94.

Stiven, A. C., Moreira, J. J. S., Silva, C. F. Óleos essenciais de uvaia (Eugenia pyriformis Cambess): avaliação das atividades microbiana e antioxidante. Eclética Quim, 2009; 34(3): 7-13.

Bergamo, L., Camargo, L. P., Canazart, D., Fernandes, C., Filho, B. A., Mussato, D., Silva, A. A. (2014). Atividade microbiológica de óleos essenciais obtidos por arraste a vapor. Revista UNINGÁ Review, v.20, n.3, p.33-39.

Thanissery, R., Kathariou, S., Smith, D. P. (2014). Rosemary oil, clove oil, and a mix of thyme-orange essential oils inhibit Salmonella and Campylobacter in vitro. O Journal of Applied Poultry Research, 23:2, 221-227.

Torres-Martinéz, R., García-Rodriguez, Y. M., Ríos-Chávez, P., Saavedra-Molina, A., López-Meza, J. E., Ochoa-Zarzosa, A., Garciglia, R. S. (2017). Antioxidant Activity of the Essential Oil and its Major Terpenes of Satureja macrostema (Moc. and Sessé ex Benth.) Briq. Pharmacognosy Magazine, 13(4): S875-S880.

Xu P., Wang K., Lu C., Dong L., Gao L., Yan M., Aibai S., Yang Y., Liu X. Protective effects of linalool against amyloid beta-induced cognitive deficits and damages in mice. Life Sciences, 2017; 174: 21-7.

Zomorodian, K., Saharkhiz, J., Pakshir, K., Immeripour, Z., Sadatsharifi, A. (2018). The composition, antibiofilm and antimicrobial activities of essential oil of Ferula assa-foetida oleo-gum-resin. Biocatalysis and Agricultural Biotechnology, 14, 300-304. 